\title{
Properties of High-Workability Concrete with Recycled Concrete Aggregate
}

\author{
Md. Safiuddin ${ }^{\mathrm{a}}$, Ubagaram Johnson Alengaram ${ }^{\mathrm{b}}, \mathbf{M d}$. Abdus Salam
}

\author{
Mohd Zamin Jumaat ${ }^{\mathrm{b}}$, Fahrol Fadhli Jaafar ${ }^{\mathrm{b}}$, Hawa Binti Saad ${ }^{\mathrm{b}}$
}

${ }^{a}$ Department of Civil and Environmental Engineering, Faculty of Engineering, University of Waterloo, 200 University Avenue West, Waterloo, Ontario, Canada N2L 3G1

${ }^{\mathrm{b}}$ Department of Civil Engineering, Faculty of Engineering, University of Malaya, 50603 Kuala Lumpur, Malaysia

Received: March 4, 2011; Revised: April 27, 2011

\begin{abstract}
This study presents the effects of recycled concrete aggregate (RCA) on the key fresh and hardened properties of concrete. RCA was used to produce high-workability concrete substituting $0-100 \%$ natural coarse aggregate (NCA) by weight. The slump and slump flow of fresh concretes were determined to ensure high workability. In addition, the compressive, flexural and splitting tensile strengths, modulus of elasticity, and permeable voids of hardened concretes were determined. The test results revealed that RCA significantly decreased the workability of concrete. RCA also affected the compressive strength, modulus of elasticity, and permeable voids of concrete. At the age of 28 days, the concrete with $100 \%$ RCA provided $12.2 \%$ lower compressive strength and $17.7 \%$ lesser modulus of elasticity than the control concrete. Also, $100 \%$ RCA increased the permeable voids of 28 -day old concrete by $8.2 \%$. However, no significant negative impact of RCA was observed on the flexural and splitting tensile strengths of concrete.
\end{abstract}

Keywords: hardened properties, natural coarse aggregate, recycled concrete aggregate, workability

\section{Introduction}

Construction developments are on its peak in the $21^{\text {st }}$ century around the globe. There are numerous sky-scrapers, bridges, roads, underground tunnels, and deep-water structures all over the world. As well, there are many other types of structure being constructed every year. To accommodate new structures, many structures built in the past centuries are being demolished and destroyed due to their limit of life span, unsuitable position in an ever-growing city, and damaged condition caused by natural disaster. The demolition of structures is generating concrete rubbles and causing environmental problems due to unplanned disposal and scarcity of landfill site. A large portion of the potentially useful demolition waste is disposed of in landfill site. The transport and disposal of this waste are economically and environmentally not sustainable. The similar problems are caused by the tested field-cast and excess concretes, which can be categorized under construction waste. In addition, the harvesting of aggregates for construction is depleting the natural sources and damaging the ecological balance. The quarrying activities and processes involved in the harvesting of virgin aggregates are also polluting the environment. To alleviate these problems, nowadays alternative aggregates are drawing more interest in the construction industry. In recent years, the rubbles generated from the demolition of old concrete structures ${ }^{1}$, the unused concrete returned from construction site $^{2}$, and the concrete tested in laboratory or field ${ }^{3,4}$ have been recycled as aggregate and reused for new construction in many regions of the world. The aggregates processed from concrete rubbles, returned concrete, and tested concrete are well known as recycled concrete aggregate (RCA).

The major benefits of using RCA in new construction include lower environmental pollution, reduction in the need for valuable landfill space, and conservation of resources for natural aggregates ${ }^{1,4,5}$. Moreover, the use of RCA can be more economical than natural coarse aggregate (NCA) due to lower transportation cost and reduced energy consumption ${ }^{5,6}$. This is because the transportation cost can be decreased due to the availability of RCA near to the construction sites. The energy needed for obtaining RCA is also much less than that required for the harvesting and processing of NCA.

Using RCA in concrete is economically and environmentally viable. However, RCA obtained from crushing of old concrete can exhibit inconsistent properties depending on the composition, particularly the water to cement (W/C) ratio and cement content of the original concrete. The quality of RCA is generally inferior to that of $\mathrm{NCA}^{7}$. RCA contains not only the original aggregate, but also hydrated cement paste adhered to the surface of this aggregate. This paste makes RCA more porous than NCA. The higher porosity of RCA leads to a higher porosity and water absorption in concrete ${ }^{8}$. Also, RCA can contain various contaminants such as chlorides, sulphates, carbonates, organic matters, etc., depending on the source of parent concrete. Despite the inferior quality of RCA, many researchers have shown that it can be a reliable alternative of NCA in construction, particularly for non-structural or lower level application ${ }^{1,9,10}$. Levy and Helene ${ }^{11}$ as well as Poon et al. ${ }^{12}$ have graded RCA as potentially good for use in new concrete. Properly processed RCA can be used in new concrete for pavements, shoulders, barriers, embankments, sidewalks, curbs, gutters, and bridge foundations; it can also be used in structural grade concrete, bituminous concrete, and soil-cement pavement bases ${ }^{8}$. However, the RCA obtained from demolished concrete must be strictly scrutinized to pass the acceptability criteria set in relevant specifications for a particular use. It is generally recommended that RCA should have a total contaminant level lower than $1 \%$ of the bulk mass ${ }^{13}$.

The concrete rubbles generated from demolished old buildings, and removed or demolished infrastructures such as bridges, pavements, and airport runways are the major sources of $\mathrm{RCA}^{1,14}$. In addition to the demolition concrete wastes, the excess concrete returned to the ready-mixed plant ${ }^{2}$ and the rejected precast concrete 
elements ${ }^{15}$ are the significant sources of RCA. The tested laboratorycast $^{3}$ and field-cast ${ }^{4}$ concrete specimens are also the considerable sources of RCA. The construction industry normally uses six cube or cylinder specimens for testing the compressive strength of concrete from a mixture truck. An average of $2-4 \mathrm{~m}^{3}$ of concrete is used from $1000 \mathrm{~m}^{3}$ concrete pour for fabricating concrete test specimens ${ }^{4}$. After testing, these concrete specimens are discarded, thus increasing the dosposal load for landfill site. Instead of disposing, the tested fieldcast concrete specimens can be crushed and recycled as RCA to produce concrete in an economically and environment-friendly viable way. Furthermore, the tested field-cast concrete specimens provide RCA with a much lower level of contaminants, thus making it more attarctive due to a greater degree of acceptability.

The RCA obtained from the above-stated sources has mostly been used to produce ordinary or normal-workability concrete ${ }^{1-6,9,11-15}$. In contrast, limited studies have been carried out to produce high-workability concrete using the RCA obtained from tested field-cast concrete and other sources. In this research, the RCA obtained from the tested field-cast concrete specimens was used to produce high-workability concrete substituting $0,30,50,70$ and $100 \%$ NCA by weight. The slump and slump flow of freshly mixed concretes were determined to ensure high workability. In addition, the compressive strength, splitting tensile strength, flexural strength, modulus of elasticity, and permeable voids of hardened concretes were determined to observe the effects of RCA.

\section{Research Significance}

Construction and demolition wastes generated from demolished buildings and infrastructures form one of the largest waste streams in many developed countries. The excess and tested concretes also constitute a considerable portion of construction waste, particularly in developing countries. The recycling of construction and demolition wastes as RCA resolves disposal problem, reduces landfill space, conserves natural resources, decreases transport costs, diminishes environmental pollution, and protects ecological balance. This study reports the use of RCA obtained from the tested field-cast concrete specimens to produce new concrete. The experimental research has emphasized the effects of coarse RCA on a range of fresh (slump, slump flow), mechanical (compressive, splitting tensile and flexural strengths, modulus of elasticity), and durability (permeable voids) properties, and thus assessed its suitability for use in high-workability concrete. The research findings are expected to encourage the sustainable development by using RCA in structural and non-structural concretes.

\section{Materials and Methods}

\subsection{Materials}

Crushed granite stone $(5 \mathrm{~mm}<$ aggregate size $\leq 20 \mathrm{~mm}), \mathrm{RCA}$ ( $5 \mathrm{~mm}<$ aggregate size $\leq 20 \mathrm{~mm}$ ), quartz river sand (size $\leq 5 \mathrm{~mm}$ ), ordinary portland cement (OPC), a polycarboxylate based high-range water reducer (HRWR), and normal tap water (W) were used to produce the concretes. Crushed granite stone was used as NCA and quartz river sand $(\mathrm{S})$ was used as fine aggregate (FA). The tested Grade 30 concrete cubes obtained from I-Mix Concrete Sdn. Bhd., Selangor, Malaysia were the source of RCA. The cubes were hammered and then the crushed fine and coarse particles were separated by $5-\mathrm{mm}$ sieve. The coarse RCA particles with a nominal maximum size of $20 \mathrm{~mm}$ were collected and used as coarse aggregate. NCA, RCA and FA or $\mathrm{S}$ collectively formed the skeleton of total aggregates (TA). OPC acted to bind the aggregates after reacting with water, whereas HRWR functioned to maintain high workability. The specific gravity of cement was 3.12 and that of HRWR was 1.06. The HRWR used was in liquid state and had a solid content of $13.5 \%$.
The sieve analysis of NCA, RCA, and FA was carried out according to BS $812-103.1^{16}$ to check whether they meet the BS grading requirements, and to determine their fineness modulus. The gradation (size distribution) of NCA and RCA is presented in Figure 1. It can be seen from Figure 1 that RCA did not strictly meet the BS grading requirement for coarse aggregate as specified in BS $882^{17}$. The size fraction passing $10-\mathrm{mm}$ sieve was below the specified lower limit. It suggests that RCA contained a lower fraction of fine particles. A higher fineness modulus of RCA also suggests that it had lesser fine particles than NCA.

The RCA obtained from crushed field-cast concrete cubes was more angular and had more surface roughness than NCA, as noticed during visual inspection (Figure 2). Also, the surface of RCA was more porous due to adhered cement paste. The key physical properties of RCA, NCA and FA are given in Table 1. The moisture content of NCA, RCA and FA was determined according to BS 812-10918. The open porosity of RCA and NCA was determined based on the cold-water method described in ASTM C 642-06 ${ }^{19}$. The angularity of RCA and NCA was quantified in accordance with BS 812-120. The specific gravity, bulk density and water absorption of all aggregates were determined according to BS 812-2 ${ }^{21}$. The aggregate impact value of both RCA and NCA was determined following the test procedure given in BS 812-11222. RCA had higher open porosity and water absorption than NCA due to porous surface. The angularity number of RCA was 9.50 and that of NCA was 7.50. Hence, RCA was more angular than NCA. RCA was also lighter than NCA. This is because the specific gravity and bulk density of RCA were lower than those of NCA. In addition, RCA was weaker than NCA and therefore provided a relatively high aggregate impact value. Thus, the physical properties of RCA were significantly different from those of NCA. Similar differences between the physical properties RCA and NCA were reported from earlier research ${ }^{23,24}$.

\subsection{Concrete mix proportions}

Nine (9) trial concrete mixes using NCA were prepared with different $\mathrm{W} / \mathrm{C}$ ratios $(0.50,0.60$, and 0.65$)$ and HRWR dosages to ensure high-workability. The basic mix proportions (without HRWR dosage) of these concretes were determined based on the British

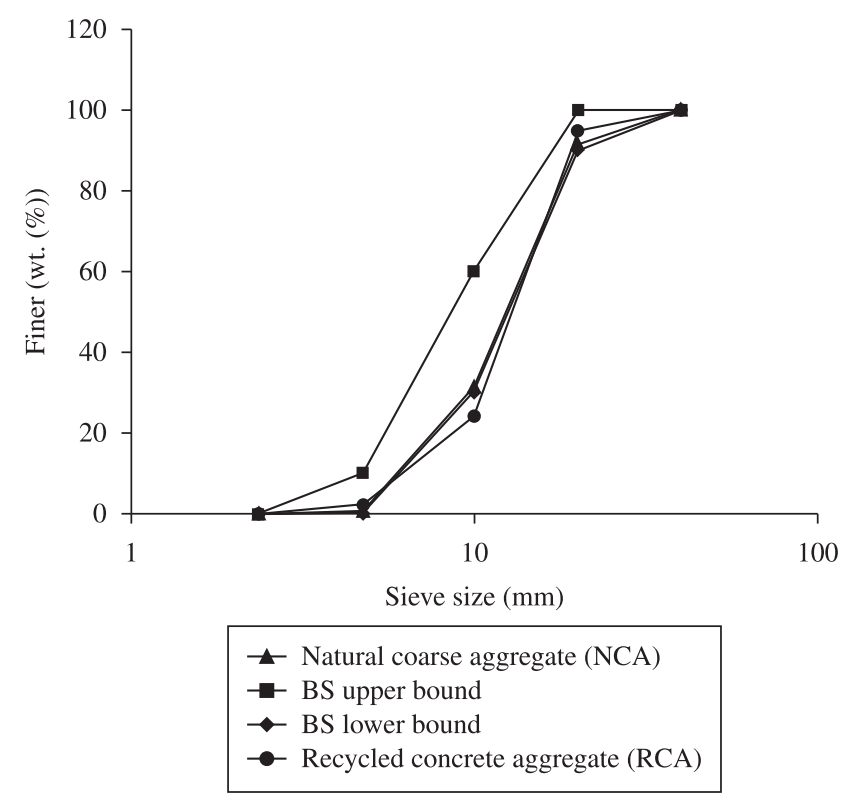

Figure 1. Gradation of RCA and NCA. 


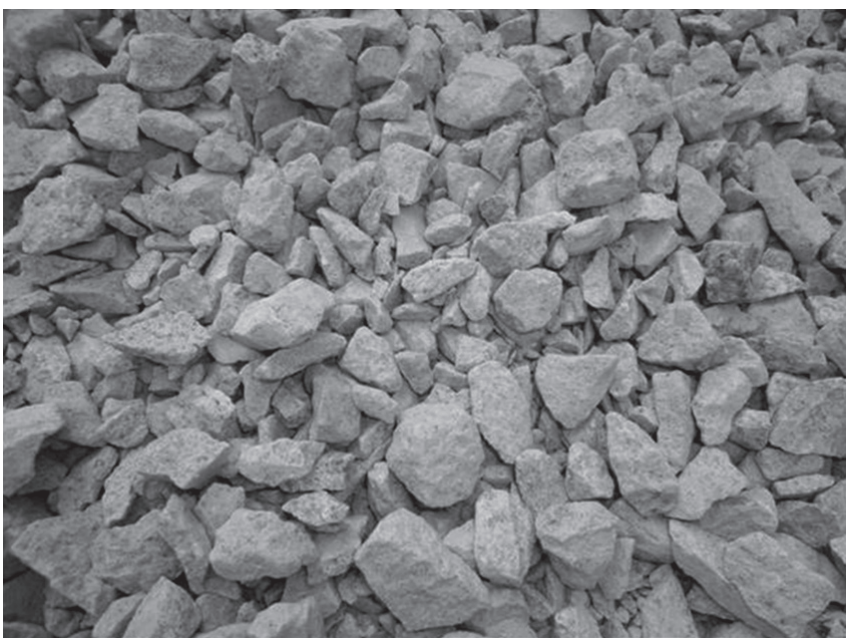

Normal coarse aggregate (NCA)

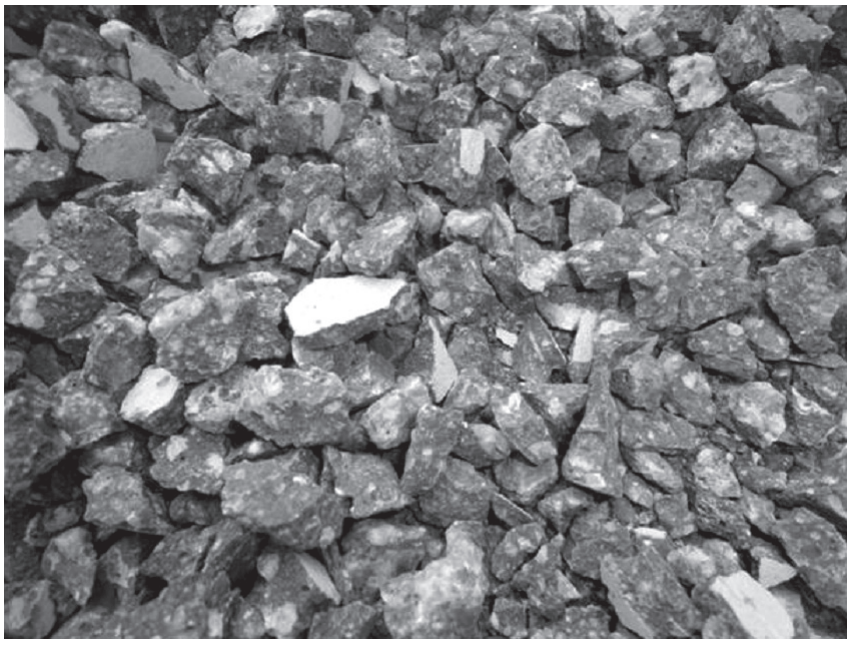

Recycled concrete aggregate (RCA)

Figure 2. Appearance of NCA and RCA.

Table 1. Basic physical properties of fine and coarse aggregates.

\begin{tabular}{cccc}
\hline Physical property & RCA & NCA & FA \\
\hline Nominal maximum size $(\mathrm{mm})$ & 20 & 20 & 5 \\
Fineness modulus & 6.79 & 6.76 & 2.88 \\
Bulk density in compacted condition $\left(\mathrm{kg} . \mathrm{m}^{-3}\right)$ & 1250 & 1510 & 1620 \\
Saturated surface-dry based specific gravity & 2.53 & 2.62 & 2.69 \\
Oven-dry based specific gravity & 2.48 & 2.53 & - \\
Open porosity (vol. (\%)) & 5.03 & 1.55 & - \\
Absorption (wt. (\%)) & 2.03 & 0.60 & 1.32 \\
Moisture content (wt. (\%)) & 1.57 & 0.17 & 0.31 \\
Angularity number & 9.50 & 7.50 & - \\
Aggregate impact value (wt. (\%)) & 12.7 & 10.0 & - \\
\hline
\end{tabular}

DoE (Department of Environment) mix design method ${ }^{25}$. From the trial concrete mixes, a suitable control mix ( $0 \%$ RCA) satisfying the requirements for high workability (slump $>250 \mathrm{~mm}$, slump flow $>500 \mathrm{~mm}$ ) was decided. The W/C ratio, S/A (FA/TA) ratio and HRWR dosage of the selected control mix was $0.60,0.50$ and $1.5 \%$ (by weight of cement), respectively.
Using the same W/C ratio, S/A ratio and HRWR dosage of control concrete, four different concretes were designed with RCA substituting 30,50, 70 and $100 \%$ NCA by weight. The W/C ratio, S/A ratio and HRWR dosage of these concretes were kept the same as used in the control mix to observe the effects of RCA on the concrete properties. The basic mix proportions of these concretes were calculated based on the absolute volume of constituent materials and $2 \%$ entrapped air content. Before preparing the concretes, the basic mix proportions were corrected considering the water absorption and moisture content of aggregates, and the water contribution of HRWR. The corrected mix proportions of control and RCA concretes are given in Table 2. The concretes were designated based on the RCA content. For example, the CRCA50 designation was used for a concrete including 50\% RCA as a partial replacement of NCA.

\subsection{Preparation and testing of fresh concretes}

A rotary pan mixer was used to prepare the concretes. The mixer was dampened to prevent the loss of mix water during mixing. Coarse and fine aggregates were put in the mixer pan and homogenized for 1 minute in dry condition. The mixer was covered with a lid to prevent dust from fluttering. Then the first half of the mix water was added into the mixer and the mixing was continued for 1 minute. Thereafter, the mixer was stopped for 1 minute to allow the absorption of water into aggregates. Then the cement was added and the mixing was resumed for another 1 minute. Later the second half of the mix water blended with HRWR dosage was introduced and the mixing was continued for 2 minutes followed by 2 minutes rest. Finally, the concrete was mixed for additional 2 minutes to complete the mixing operation. The net mixing time excluding the rest periods was 7 minutes.

Immediately after the completion of mixing, the slump and slump flow of fresh concretes were determined to ensure high workability. The slump test was carried out in accordance with BS 1881-102 ${ }^{26}$. Using the same sample that collapsed during the slump test, the slump flow was also determined by measuring the largest and corresponding perpendicular diameters of concrete spread. The slump flow was determined to clearly observe the effect of RCA on the workability of concrete.

\subsection{Preparation of test specimens and testing of hardened concretes}

Cube, prism and cylinder specimens were cast after testing the fresh concretes. $100 \mathrm{~mm}$ cubes, $\varnothing 100 \times 200 \mathrm{~mm}$ cylinders, and $100 \times 100 \times 500 \mathrm{~mm}$ prisms were cast in two layers, instead of three layers, due to relatively high workability. However, $\varnothing 150 \times 300 \mathrm{~mm}$ cylinder specimens were cast in three layers because of a larger depth. In all cases, multi-use metal (cast iron) moulds were used. The specimens were de-moulded at the age of 1 day and immersed in water for curing until the day of testing. At the day of testing, several $\varnothing 100 \times 200 \mathrm{~mm}$ cylinder specimens were cut to prepare $\varnothing 100 \times 50 \mathrm{~mm}$ cylinders needed for testing the permeable voids of concrete. While cutting, thin sections from top and bottom were discarded to minimize the end effects. Three $\varnothing 100 \times 50 \mathrm{~mm}$ cylinder specimens were obtained from each $\emptyset 100 \times 200 \mathrm{~mm}$ cylinder.

The compressive, flexural and splitting tensile strengths, static modulus of elasticity, and permeable voids of hardened concretes were examined at the age of 7 and 28 days. The compressive strength test was performed in accordance with BS1881-116 $6^{27}$ using $100 \mathrm{~mm}$ cube specimens. The splitting tensile strength test was carried out according to BS $1881-117^{28}$ using $\varnothing 150 \times 300 \mathrm{~mm}$ cylinder specimens. The test procedure given in BS1881-118 ${ }^{29}$ was used to determine the flexural strength using $100 \times 100 \times 500 \mathrm{~mm}$ prisms. The static modulus of elasticity was determined in accordance with BS $1881-121^{30}$ using $\varnothing 150 \times 300 \mathrm{~mm}$ cylinders. The permeable voids were determined 
Table 2. Mix proportions of different concrete mixes.

\begin{tabular}{cccccccc}
\hline Mix & $\begin{array}{c}\text { NCA } \\
\left(\mathrm{kg} \cdot \mathrm{m}^{-3}\right)\end{array}$ & $\begin{array}{c}\text { RCA } \\
\left(\% \mathrm{CA}^{\dagger}\right)\end{array}$ & $\begin{array}{c}\text { RCA } \\
\left(\mathrm{kg} \cdot \mathrm{m}^{-3}\right)\end{array}$ & $\begin{array}{c}\text { FA } \\
\left(\mathrm{kg} \cdot \mathrm{m}^{-3}\right)\end{array}$ & $\begin{array}{c}\text { OPC } \\
\left(\mathrm{kg} \cdot \mathrm{m}^{-3}\right)\end{array}$ & $\begin{array}{c}\mathrm{W} \\
\left(\mathrm{kg} \cdot \mathrm{m}^{-3}\right)\end{array}$ & $\begin{array}{c}\mathrm{HRWR} \\
\left(\% \mathrm{C}^{\ddagger}\right)\end{array}$ \\
\hline CRCA0 & 910.1 & 0 & 0 & 904.9 & 342 & 213.6 & 1.5 \\
CRCA30 & 609.1 & 30 & 260.9 & 864.7 & 342 & 213.1 & 1.5 \\
CRCA50 & 433.1 & 50 & 433.0 & 861.3 & 342 & 213.2 & 1.5 \\
CRCA70 & 258.8 & 70 & 603.5 & 857.5 & 342 & 213.2 & 1.5 \\
CRCA100 & 0 & 100 & 856.6 & 851.9 & 342 & 213.1 & 1.5 \\
\hline
\end{tabular}

${ }^{\circ} \mathrm{CA}=\mathrm{NCA}+\mathrm{RCA} ; \mathrm{C}=\mathrm{OPC}$

by testing $\varnothing 100 \times 50 \mathrm{~mm}$ cylinder specimens according to the test procedure described in Safiuddin and Hearn ${ }^{31}$. Triplicate specimens were used in all tests.

\section{Results and Discussion}

\subsection{Fresh properties}

\subsubsection{Workability}

The workability of concrete was evaluated with respect to slump and slump flow. The slump ranged from 255 to $275 \mathrm{~mm}$, which indicate a high workability of concrete. The slump flow results also reveal that the concretes were highly workable. In this study, the slump flow varied in the range of 505-620 mm. High-workability concrete generally provides a slump higher than $200 \mathrm{~mm}$ and a slump flow greater than $500 \mathrm{~mm}^{32}$. Adequate HRWR dosage was used to maintain high workability. The polycarboxylate-based HRWR dispersed the cement particles by its steric hindrance effect induced by long grafted side-chain, thus reducing the loss of water due to entrapping in cement flocks. Therefore more free water was available in freshly mixed concrete to maintain high workability.

The use of RCA decreased the slump and slump flow of concrete, as can be seen from Figures 3 and 4, respectively. In general, the overall slump and slump flow results reveal that a higher RCA content produced a lower workability. Similar results were observed in earlier research on normal-workability concrete ${ }^{3,15,23}$. This is credited to the physical characteristics of RCA particles. The RCA used in the present study was more angular and porous, and much rougher than NCA due to the adhered cement paste. The rough-textured RCA particles increased the harshness of concrete mix, and thus decreased its workability, particularly at a greater content. In addition, the deficient gradation of RCA contributed to decrease the workability of concrete. The RCA had much coarse but less fine particles than NCA (Figure 1). The dispersion of aggregates consisting of relatively a high content of coarse particles can be lower due to increased interparticle collisions ${ }^{33}$. The loss of cement paste into the surface pores of RCA also decreased the workability of concrete.

Among four RCA concretes, 30 and 50\% RCA contents provided slightly better slump and slump flow than 70 and $100 \%$ RCA contents. This is highly credited to the reduced contents of fine and coarse aggregates (refer to Table 2). The deformability of concrete improves at a lower aggregate content ${ }^{34}$. However, this effect was nullified in case of 70 and $100 \%$ RCA contents due to the adverse physical characteristics (angularity, surface roughness, open porosity, etc.) of RCA. Therefore, the lowest level of workability was observed for the concretes including 70 and $100 \%$ RCA contents.

\subsection{Hardened properties}

The hardened properties reported in this study are for the concretes including coarse RCA, which was obtained from a single

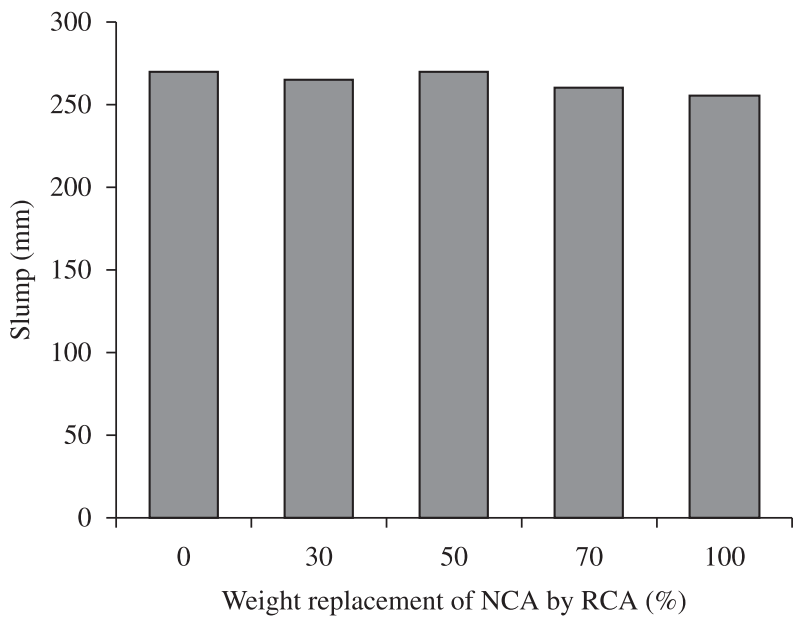

Figure 3. Slump of concrete for different RCA contents.

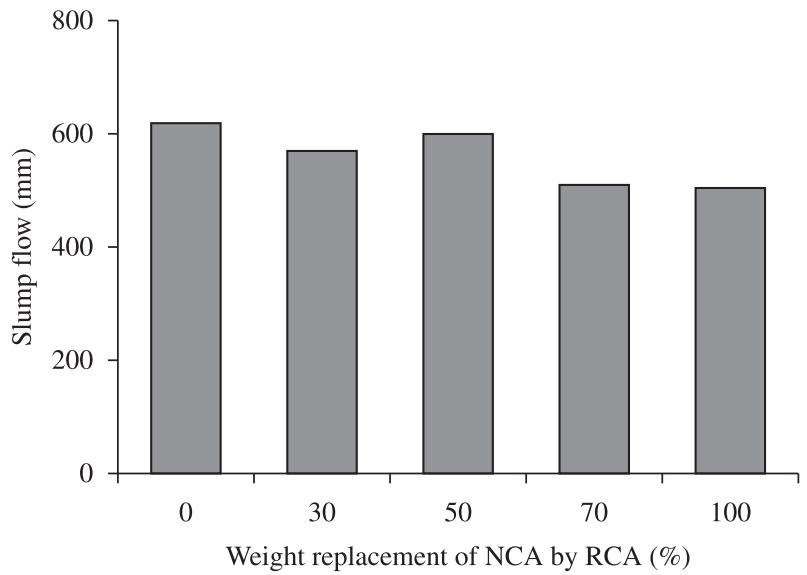

Figure 4. Slump flow of concrete for different RCA contents.

source. Similar results with identical trends are expected for the other sources of RCA whose physical properties are equivalent to the physical properties of RCA used in the present study.

\subsubsection{Compressive strength}

The test results for the 7 and 28 days compressive strengths of concretes are presented in Figure 5. This figure shows that the 28 days compressive strength was higher than the 7 days compressive strength. This is due to the increased amount of hydration products with the longer curing age. However, the increase in compressive strength was not very significant at the age of 28 days. The 7-day compressive strength is generally $60-80 \%$ of the 28 -day compressive 
strength in the case of normal concrete cured under standard moist or water curing ${ }^{35-36}$. In this study, the maximum increase in the compressive strength at 28 days was only about $13.2 \%$ as compared with 7 days compressive strength. A similar result was obtained in an earlier research ${ }^{31}$. The concretes produced in the present study contained comparatively high cement content at a higher W/C ratio. The recommended minimum cement content is $270 \mathrm{~kg} \cdot \mathrm{m}^{-3}$ for normal strength high-workability concrete ${ }^{37}$. The cement content used in the present study was $342 \mathrm{~kg} . \mathrm{m}^{-3}$, which is relatively high. A high cement content contributes to produce a greater early-age compressive strength $^{38}$. In addition, high-workability concrete generally provides a greater early-age compressive strength than normal-workability concrete due to enhanced strength development and better compactability $^{39}$. The results of permeable voids (see Section 4.2.5.) also suggest that the pore structure of concrete was not improved at the age of 28 days due to relatively less additional hydration products and leaching out of portlandite (calcium hydroxide, $\mathrm{Ca}(\mathrm{OH})_{2}$ ). Therefore, no significant improvement in the microstructure of concrete occurred after 7 days to produce a substantially greater compressive strength at 28 days.

RCA had no significant negative impact on the compressive strength of concrete, as evident from Figure 5. The concretes with and without RCA provided a similar compressive strength, except for $100 \%$ RCA. The concrete with $100 \%$ RCA provided a lower compressive strength than the control concrete, particularly at 28 days. However, the reduction in the 28-day compressive strength observed in the present study was only $12.2 \%$ in comparison with the control concrete. A similar finding was reported in the case of normal-workability RCA concrete ${ }^{2,3,40}$. Although RCA was inferior to NCA due to porous surface caused by adhered cement paste, it did not significantly decrease the compressive strength of concrete. This is due to a better interfacial bond between aggregate and cement paste in the presence of rough $\mathrm{RCA}^{6,9}$. In addition, a better interlocking of aggregates can be obtained because of angular RCA. These two effects may contribute to counterbalance the decrease in compressive strength due to less strong RCA. It is apparent from Table 1 that RCA was more angular than NCA. Also, a visual inspection of coarse aggregates revealed that RCA had a greater surface roughness than NCA (refer to Figure 2). Both of these properties are conducive to the compressive strength of concrete. Nevertheless, the weakness of RCA due to porous adhered cement paste prevailed over its surface roughness and angularity at $100 \%$ RCA, thus showing a decrease in the compressive strength of concrete. In addition, the deficient gradation of RCA contributed to provide a lower compressive strength by affecting the physical packing of concrete at a lower workability.

\subsubsection{Flexural strength}

The test results for the flexural strength of concrete are presented in Figure 6. In general, 28 days flexural strength was greater than 7 days flexural strength. The maximum increase in the flexural strength at 28 days was $17.3 \%$ as compared with 7 days flexural strength. This is due to the additional hydration products, as mentioned in the case of compressive strength. It is also obvious from Figure 6 that RCA did not produce any significant negative impact on the flexural strength of concrete. Identical results were noticed in earlier research on normal-workability RCA concrete ${ }^{3,15}$. It is due to the similar reasons as discussed in the case of compressive strength. The aggregate characteristics (surface roughness, angularity, etc.) of RCA contribute to produce better interfacial bond and mechanical interlocking. In addition, the coarse aggregates are generally oriented with their larger dimension along the length of the prism specimen. It implies that the interfacial bond is more effective along the specimen length. Therefore, a greater restraint to the flexure (bending) occurred, thus compensating the negative impact of the weakness of RCA on the modulus of rupture (flexural strength) of concrete. As a result, the comparable flexural strength was obtained for the concretes with and without RCA.

\subsubsection{Splitting tensile strength}

The results for the splitting tensile strength are shown in Figure 7 . This figure shows that 28 days splitting tensile strength was significantly greater than 7 days splitting tensile strength. The maximum increase in the splitting tensile strength at 28 days was $40.3 \%$ in comparison with 7 days splitting tensile strength. The increase in 28 days splitting tensile strength was relatively high in the presence of RCA. It is due to the combined effect of increased hydration products and favourable physical characteristics of RCA. Figure 7 also reveals that RCA produced no significant negative impact on the splitting tensile strength of concrete, particularly at the age of 28 days. Similar findings were reported from earlier research on normal-workability RCA concrete ${ }^{9,15,24}$. This is because of the similar reasons as discussed in the cases of compressive and flexural strengths. An equivalent or better splitting tensile strength

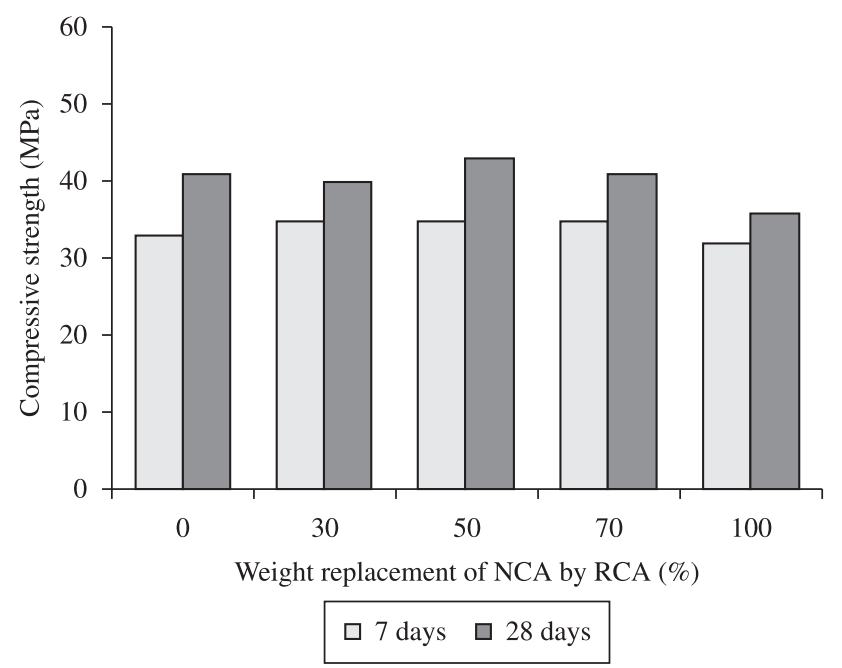

Figure 5. Compressive strength of concrete for different RCA contents.

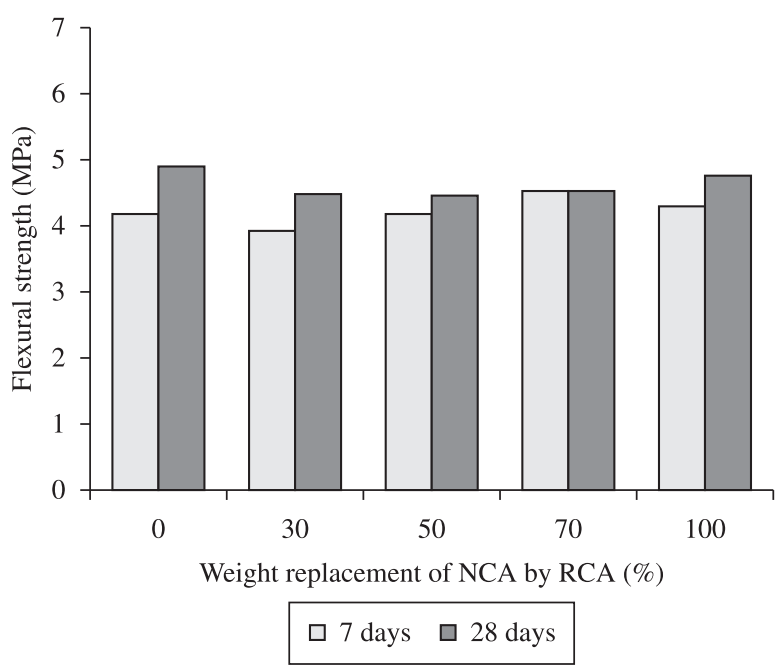

Figure 6. Flexural strength of concrete for different RCA contents. 
can be obtained in the presence of RCA owing to good interfacial bond between aggregate and mortar matrix ${ }^{9}$. Also, Tavakoli and Soroushian ${ }^{41}$ mentioned that the splitting tensile strength can be higher for RCA concrete if the RCA is derived from a concrete, which was produced for a compressive strength higher than that of control concrete. In the present study, the parent concrete of RCA and control concrete had identical compressive strength. Hence, the RCA concretes produced in this study are not expected to provide a higher splitting tensile strength than the control (non-RCA) concrete. Indeed, the present study shows that there was some decrease in the splitting tensile strength at the age of 7 days. This may be due to the reason that the immature concrete was weaker in the facture plane because of porous microstructure in the presence of RCA. Nevertheless, this effect became less detrimental with the maturity of concrete. As a result, the 28 days splitting tensile strength was comparable for the concretes with and without RCA (refer to Figure 7).

\subsubsection{Modulus of elasticity}

The test results for the modulus of elasticity of concretes are presented in Figure 8. These results are consistent with the strength results. A higher modulus of elasticity is generally obtained with a greater strength. Therefore, the modulus of elasticity at 28 days was higher than that at 7 days. However, the increase in the modulus of elasticity was not as significant as the increases in flexural and splitting tensile strengths. The maximum increase in 28 days modulus of elasticity was $11.8 \%$ in comparison with 7 days modulus of elasticity. The reasons are the same as explained before in the cases of strength properties.

The effect of RCA on the modulus of elasticity of concrete is evident from Figure 8. This figure shows that relatively low values of modulus of elasticity were obtained for the RCA concretes. This is because RCA was more porous and less strong than NCA (see Table 1). The modulus of elasticity decreased with the increase in RCA content. Similar results were obtained in earlier studies on normal-workability RCA concrete ${ }^{2,15}$. In the present study, the lowest modulus of elasticity at both ages was obtained for the concrete with $100 \%$ RCA. In this case, the reduction in the 28-day modulus of elasticity was $17.7 \%$ as compared with the control concrete. According to Hansen ${ }^{42}$, the modulus of elasticity of RCA concrete can be 15-50\% lower than that of non-RCA concrete. Also, Aitcin and Mehta $^{43}$ reported that the concrete produced with less strong aggregates possesses a lower modulus of elasticity.

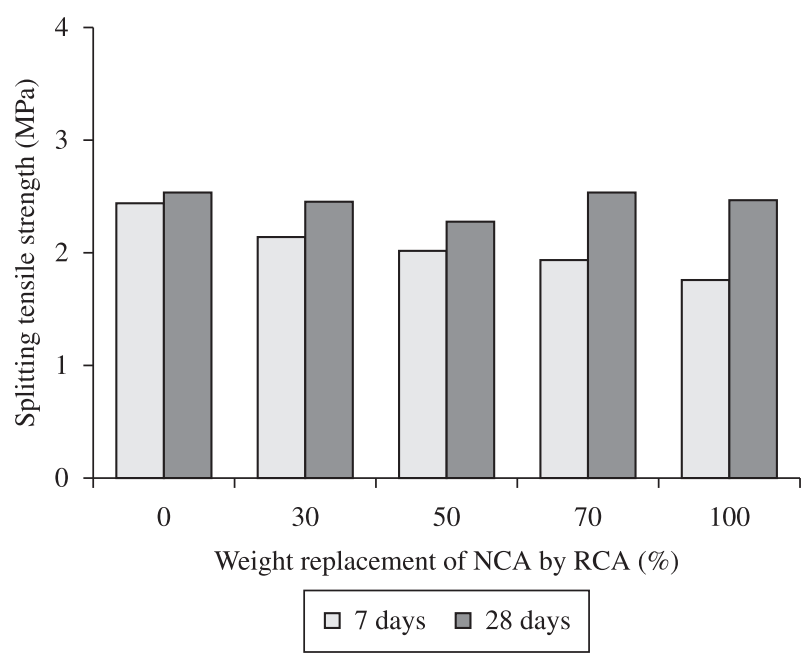

Figure 7. Splitting tensile strength of concrete for different RCA contents.
The modulus of elasticity of concrete is influenced by the moduli of hardened cement paste and aggregate. In the present study, the effect of the modulus of elasticity of hardened cement paste was unlikely, since the paste parameters (paste volume, W/C ratio, cement content, and water content) remained the same for all concretes. It suggests that the modulus of elasticity of combined aggregates affected the modulus of elasticity of concrete due to the presence of RCA. Since RCA is more porous and less strong than NCA, it would have a lower modulus of elasticity ${ }^{15}$. A lower modulus of elasticity of aggregate decreases the modulus of elasticity of concrete ${ }^{36}$. As a result, the RCA concretes exhibited a lower modulus of elasticity.

\subsubsection{Permeable voids}

The permeable voids of different concretes are presented in Figure 9. In general, no reduction in the permeable voids of concrete occurred after 7 days. In fact, the 28 days permeable voids slightly increased in all cases. The compressive strength results suggest that no significant pore refinement occurred after 7 days due to the relatively high W/C ratio. The volume of capillary pores and their connectivity significantly increase for a W/C ratio greater than $0.40^{44,45}$. It suggests that the pore connectivity was substantially higher

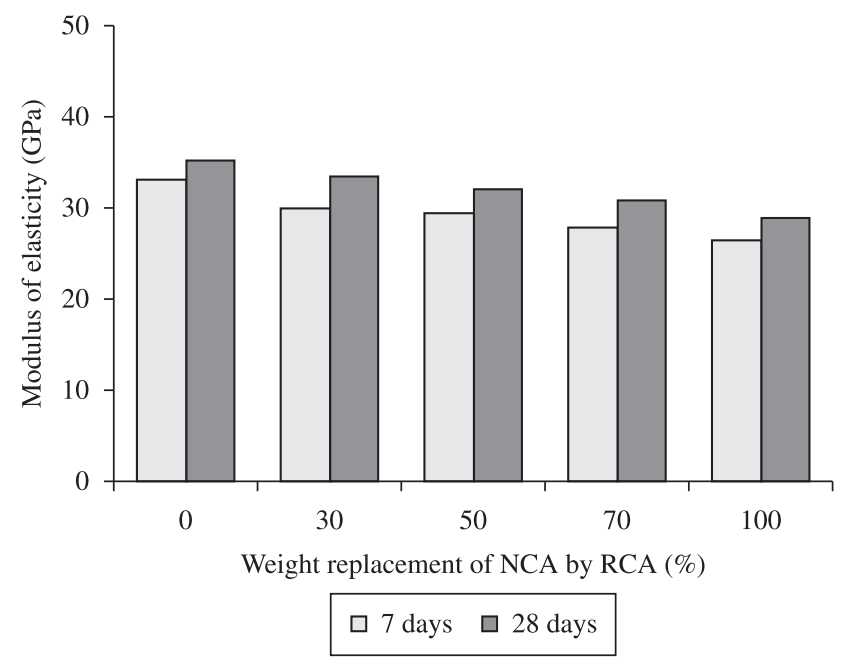

Figure 8. Modulus of elasticity of concrete for different RCA contents.

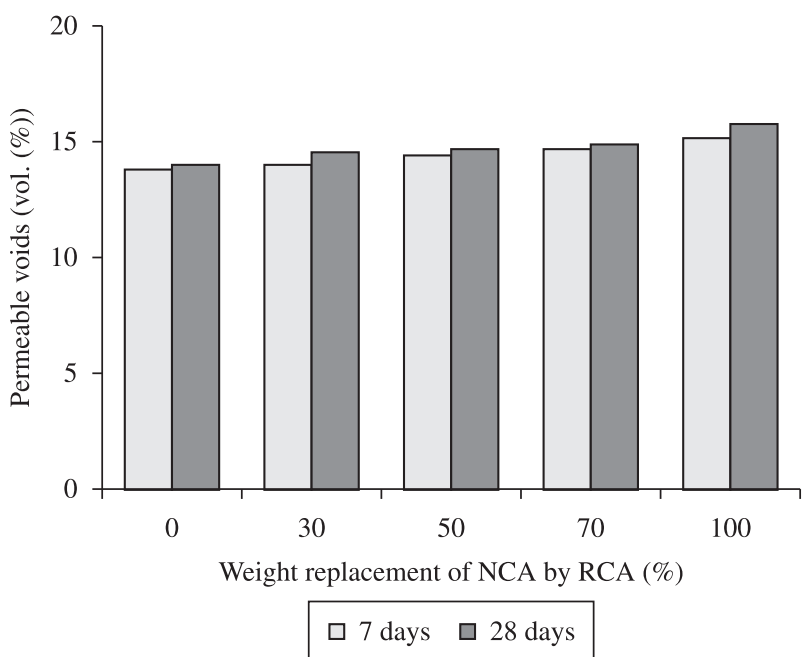

Figure 9. Permeable voids of concrete for different RCA contents. 
at the W/C ratio of 0.60 used in the present study. The increased pore connectivity enhanced the leaching out of portlandite (calcium hydroxide, $\mathrm{Ca}(\mathrm{OH})_{2}$, which is liberated from cement hydration) from the specimens immersed in water. Also, no saturated lime water was used during curing; it accelerated the leaching out of portlandite, thus leaving some pores in concrete. Consequently, there was no decrease in the permeable voids of concrete at the age of 28 days.

The permeable voids of concrete gradually increased with the increase in RCA content, as evident from Figure 9. The highest level of permeable voids was obtained for the concrete with $100 \%$ RCA. At the age of 28 days, it provided $8.2 \%$ more permeable voids than the control (non-RCA) concrete. Limited research investigated the effect of RCA on the permeable voids of concrete. However, a number of published papers reported that the absorption and permeability properties of concrete increase in the presence of $\mathrm{RCA}^{2,9,15}$. These findings suggest that the RCA concrete possesses a higher volume of permeable voids. The increase in the permeable voids is mostly due to the higher porosity of RCA. The RCA contained adhered cement paste, which makes the RCA porous and thereby increases the overall porosity of concrete. As a result, the measured permeable voids at both ages were greater for the RCA concretes.

\section{Conclusions}

RCA can overcome the shortage of NCA, eliminate the harvesting cost of NCA, and reduce the construction and demolition wastes in landfill site. In addition, it will eradicate the transportation cost for gathering NCA to construction site, and for disposing the construction and demolition wastes to landfill site. RCA was used in the present study as partial and full replacements of NCA to produce high-workability concretes. The effects of RCA on the workability, compressive strength, flexural strength, splitting tensile strength, modulus of elasticity, and permeable voids of concrete were investigated. The following conclusions can be drawn based on the findings of the experimental investigation:

1. RCA reduced the workability of concrete; the decreases in slump and slump flow were higher at a greater RCA content. The angular and rough-textured RCA particles increased the harshness of concrete mix, and thus decreased its slump and slump flow. In addition, the deficient gradation of RCA was partly responsible to reduce the workability of concrete;

2. In general, no significant improvement in compressive strength and modulus of elasticity occurred at the age of 28 days, as the concretes were produced with relatively a high W/C ratio. Also, the leaching out of portlandite during water curing may be partly responsible for no significant improvement in these two hardened properties after 7 days. Due to the similar reasons, no decrease in the permeable voids of concrete occurred at the age of 28 days;

3. RCA produced no significant adverse effect on the compressive strength of concrete; the maximum decrease in 28 days compressive strength was only $12.2 \%$ for $100 \%$ RCA. Although RCA was weaker than NCA and had a deficient gradation, the enhanced interfacial bond and mechanical interlocking contributed to overcome these drawbacks, thus producing no substantial negative impact on compressive strength;

4. The flexural strength of concrete was not affected in the presence of RCA due to the better mechanical interlocking and interfacial bond resulting from angular and rough-textured RCA. Also, a greater restraint to the flexure (bending) occurred due to more effective interfacial bond along the specimen length;
5. The splitting tensile strength of concrete at the age of 28 days was not affected in the presence of RCA, particularly at the age of 28 days. This is due to the enhanced mechanical interlocking and interfacial bond produced by the increased angularity and surface roughness of RCA;

6. The modulus of elasticity of concrete decreased when RCA was used as a partial or full replacement of NCA; a higher RCA content caused a greater decrease in the modulus of elasticity. This is attributed to the lower elastic modulus of RCA, since it was weaker and more porous than NCA;

7. The permeable voids of concrete increased with the increase in RCA content. This is mostly credited to the higher porosity of RCA; the adhered cement paste made the RCA porous and thus increased the overall permeable voids of concrete; and

8. RCA can be used in producing new concrete with acceptable fresh and hardened properties, thus encouraging the sustainable development.

\section{Acknowledgements}

The authors are grateful to I-Mix Concrete Sdn. Bhd., Selangor, Malaysia for providing the tested field-cast concrete cubes, which were used to obtain RCA. The authors are also thankful to Sika Kimia Sdn. Bhd. for the supply of HRWR used in the research.

\section{References}

1. Rao A, Jha KN, Mishra S. Use of aggregates from recycled construction and demolition waste in concrete. Resources, Conservation and Recycling. 2007; 50(1):71-81. http://dx.doi.org/10.1016/j.resconrec.2006.05.010

2. Obla KH, Kim H. Sustainable concrete through reuse of crushed returned concrete. TRB Transportation Research Record. 2009; 2113:114-121. http://dx.doi.org/10.3141/2113-14

3. Limbachiya MC, Koulouris A, Roberts JJ, Fried AN. Performance of recycled aggregate concrete. In: RILEM International Symposium on Environment-Conscious Materials and Systems for Sustainable Development; 2004; Koriyama, Japan. Baneux, France: RILEM Publications SARL; 2004. p. 127-136.

4. Yong PC, Teo DCL. Utilisation of recycled aggregate as coarse aggregate in concrete. UNIMAS E-Journal of Civil Engineering. 2009; 1(1):1-6.

5. Shayan A, Xu A. Performance and properties of structural concrete made with recycled concrete aggregate. ACI Materials Journal. 2003; 100(5):371-380.

6. Tabsh SW, Abdelfatah AS. Influence of recycled concrete aggregates on strength properties of concrete. Construction and Building Materials. 2009; 23(2):1163-1167. http://dx.doi.org/10.1016/j. conbuildmat.2008.06.007

7. Kou SC, Poon CS. Properties of self-compacting concrete prepared with coarse and fine recycled concrete aggregates. Cement and Concrete Composites. 2009; 31(9):622-627. http://dx.doi.org/10.1016/j. cemconcomp.2009.06.005

8. Portland Cement Association - PCA. Recycled aggregate. In: Concrete Technology. Illinois: PCA. Available from: <http://testinter.cement.org/ tech/>. Access in: May 13, 2010.

9. Sagoe-Crentsil KK, Brown T, Taylor AH. Performance of concrete made with commercially produced coarse recycled concrete aggregate. Cement and Concrete Research. 2001; 31(5):707-712. http://dx.doi.org/10.1016/ S0008-8846(00)00476-2

10. Tu T-Y, Chen Y-Y, Hwang C-L. Properties of HPC with recycled aggregates. Cement and Concrete Research. 2006; 36(5):943-950. http://dx.doi.org/10.1016/j.cemconres.2005.11.022

11. Levy SM, Helene P. Durability of recycled aggregates concrete: a safe way to sustainable development. Cement and Concrete Research. 2004; 34(11):1975-1980. http://dx.doi.org/10.1016/j.cemconres.2004.02.009 
12. Poon C, Kou S, Lam L. Influence of recycled aggregate on slump and bleeding of fresh concrete. Materials and Structures. 2007; 40(9):981-988. http://dx.doi.org/10.1617/s11527-006-9192-y

13. Cement Concrete \& Aggregates Australia - CCAA. Use of Recycled Aggregates in Construction. Sydney, Australia: CCAA; 2008.

14. Anderson KW, Uhlmeyer JS, Russell M. Use of Recycled Concrete Aggregate in PCCP: Literature Search. Washington: Washington State Department of Transportation; 2009. Special Report WA-RD 726.1.

15. Malešev M, Radonjanin V, Marinkovic S. Recycled concrete as aggregate for structural concrete production. Sustainability. 2010; 2(5):1204-1225.

16. British Standards Institution. BS 812-103.1: Testing aggregates-part 103: methods for determination of particle size distribution-section 103.1: sieve tests. London: British Standards Institution; 1985.

17. British Standards Institution. BS 882: Specification for aggregates from natural sources for concrete. London: British Standards Institution; 1992.

18. British Standards Institution. BS 812-109: Testing aggregates-part 109: methods for determination of moisture content. London: British Standards Institution; 1990.

19. American Society for Testing and Materials. ASTM C 642-06: Standard test method for desnity, absorption, and voids in hardened concrete. Philadelphia: American Society for Testing and Materials; 2006.

20. British Standards Institution. BS 812-1: Testing aggregates-part 1: methods for determination of particle size and shape. London: British Standards Institution; 1975.

21. British Standards Institution. BS 812-2: Testing aggregates-part 2: methods of determination of density. London: British Standards Institution; 1995.

22. British Standards Institution. BS 812-112: Testing aggregates-part 112: methods for determination of aggregate impact value. London: British Standards Institution; 1990.

23. Topçu IB, Sengel S. 2002. Properties of concrete produced with waste concrete aggregate. Cement and Concrete Research. 2002; 34(8):1307-1312.

24. Gonzalez FB, Martinez AF. Concrete with aggregates from demolition waste and silica fume. Materials and mechanical properties. Building and Environment. 2006; 43:429-437.

25. British Department of the Environment - DoE. Design of normal concrete mixes. Watford: British Department of the Environment, The Building Research and Establishment (BRE) Publication; 1975.

26. British Standards Institution. BS 1881-102: Testing concrete-part 102: method for determination of slump. London: British Standards Institution; 1983.

27. British Standards Institution. BS 1881-116: Testing concrete-part 116 : method for determination of compressive strength of concrete cubes. London: British Standards Institution; 1983.

28. British Standards Institution. BS 1881-117: Testing concrete-part 117: method for determination of tensile splitting strength. London: British Standards Institution; 1983.

29. British Standards Institution. BS 1881-118: Testing concrete-part 118 method for determination of flexural strength. London: British Standards Institution; 1983.
30. British Standards Institution. BS 1881-121: Testing concrete-part 121: method for determination of static modulus of elasticity in compression. London: British Standards Institution; 1983.

31. Safiuddin Md, Hearn N. Comparison of ASTM saturation techniques for measuring the permeable porosity of concrete. Cement and Concrete Research. 2005; 35(5):1008-1013.

32. Zain MFM, Safiuddin Md, Yusof KM. A study on the properties of freshly mixed high performance concrete. Cement and Concrete Research. 1999; 29(9):1427-1432. http://dx.doi.org/10.1016/S0008-8846(99)00108-8

33. Safiuddin Md. Development of Self-consolidating High Performance Concrete Incorporating Rice Husk Ash. [Ph.D. Thesis]. Waterloo: University of Waterloo; 2008.

34. Safiuddin Md, West JS, Soudki KA. Self-Consolidating High Performance Concrete with Rice Husk Ash: Components, Properties, and Mixture Design. Saarbrücken, Germany: VDM Publishing House Ltd.; 2009.

35. Mindess S, Young JF, Darwin D. Concrete. 2nd ed. New Jersey: Prentice Hall; 2003.

36. Neville AM. Properties of Concrete. 4th ed. New York: John Wiley \& Sons, Inc.; 1996.

37. Japanese Society of Civil Engineering - JSCE. Guide to Construction of Flowing Concrete. Tokyo, Japan: Gihoudou Publication; 1998.

38. Rodden RA, Lange DA, Grasley ZC. Guiding Principles for the Optimization of the OMP PCC Mix Design. Illinois: Centre of Excellence for Airport Technology, University of Illinois at Urbana Champaign; 2005. Technical note, no. 12.

39. Sukumar S, Nagamani K, Raghavan RS. Evaluation of strength at early-ages of self-compacting concrete with high volume fly ash. Construction and Building Materials. 2008; 22(7):1394-1401. http://dx.doi.org/10.1016/j.conbuildmat.2007.04.005

40. Rasheeduzzafar IB, Khan A. Recycled concrete - a source of new concrete. ASTM Cement, Concrete and Aggregates. 1984; 6(1):17-27.

41. Tavakoli M, Soroushian P. Strengths of recycled aggregate concrete made using field-demolished concrete as aggregate. ACI Materials Journal. 1996; 93(2):182-190.

42. Hansen TC. Recycled aggregates and recycled aggregate concrete. Second state-of-the-art report, developments 1945-1985. Materials and Structures. 1986; 19(3):201-246. http://dx.doi.org/10.1007/BF02472036

43. Aitcin P-C, Mehta PK. Effect of coarse-aggregate characteristics on mechanical properties of high-strength concrete. ACI Materials Journal. 1990; 87(2):103-107.

44. Hearn N, Hooton RD, Mills RH. Pore structure and permeability. In: Lamond JF, Pielert JH, editors. Significance of Tests and Properties of Concrete and Concrete-Making Materials, ASTM STP 169C. Philadelphia: American Society for Testing and Materials; 1994. p. 238-253.

45. Navi P, Pignat C. Simulation of cement hydration and the connectivity of the capillary pore space. Advanced Cement Based Materials. 1996; $4(2): 58-67$. 